\title{
Partisipasi Masyarakat dalam Pengelolaan Sampah Menjadi Gas Metan di Desa Tlekung, Kecamatan Junrejo, Kota Batu
}

\author{
Salma Afifah ${ }^{1^{*}}$, Edisty Anindira ${ }^{2}$, Elvara Hana $^{3}$, Haldi Priya ${ }^{4}$, M. Jalaludin ${ }^{5}$, Nur Aini $^{6}$, \\ Nurul Fadlilatus ${ }^{7}$, Satti Wagistina ${ }^{8}$ \\ 1,2,3,4,5,67 Program Studi Sarjana Pendidikan Geografi Fakultas Ilmu Sosial Universitas Negeri Malang, Malang \\ ${ }^{8}$ Dosen Geografi Fakultas Ilmu Sosial Universitas Negeri Malang, Malang \\ *Koresponden E-mail: salma.afifah.1807216@students.um.ac.id
}

(Diterima 20 Desember 2020 | Disetujui 28 Mei 2021 | Diterbitkan 17 Juli 2021)

\begin{abstract}
Since 2009, Tlekung Village has been used as a Final Disposal Site for rubbish, which has the main problem, namely the problem of the sting smell due to a pile of trash. The purpose of this research is to find out how the TPA Tlekung manages waste and overcomes the problem of the smell of rubbish and how the community participates in waste management. The method in this research was a survey method with analysis techniques using descriptive methods. The results of the research showed that the community had participated in the form of rubbish shelter with a percentage of $56.6 \%$, rubbish collection with a percentage of $56.6 \%$, and the level of community participation was high with a percentage of $93.3 \%$. The conclusion of the community in Tlekung Village is the level of participation is high in reducing the smell of rubbish and participating in the management of waste into methane gas. From the results of community participation in helping to manage waste, the community gets the free flow of methane gas from TPA Tlekung.
\end{abstract}

Keywords: Waste management, Community participation, Environment, Methane gas

\section{PENDAHULUAN}

Tempat Pembuangan Akhir (TPA) Desa Tlekung memiliki timbunan sampah sekitar 475 $\mathrm{m}^{3} /$ hari. Sumber timbunan sampah selain dari masyarakat desa Tlekung juga dari sampah rumah tangga di berbagai desa di Kota Batu. Timbunan sampah tersebut menimbulkan bau menyengat. Puncak bau menyengat terjadi di musim hujan. Bau tersebut beresiko pada kunjungan wisatawan karena Desa Tlekung merupakan desa wisata.

Permasalahan bau sampah yang menyengat membutuhkan suatu solusi. Solusi yang ditawarkan dan dilakukan adalah dengan mengelola sampah menjadi produk yang dapat dimanfaatkan oleh masyarakat. Pengelolaan sampah di TPA Tlekung berkisar 66\% (Arief, 2013). Sampah yang diolah menghasilkan produk berupa gas metan, pupuk kompos, dan limbah lindi yang diolah menjadi pupuk cair.

TPA Tlekung memiliki 23 tenaga kerja pemilah sampah, akan tetapi masih menimbulkan suatu permasalahan. Permasalahan yang terjadi di TPA Tlekung adalah jumlah tenaga kerja yang tidak mencukupi untuk mengolah sampah. Untuk mengatasinya dibutuhkan partisipasi masyarakat Desa Tlekung dan suatu inovasi untuk mengolah sampah menjadi gas metan untuk mengurangi dampak bau dari timbunan sampah. Mengingat bahwa sampah domestik juga dihasilkan oleh rumah tangga, maka masyarakat berperan sebagai agen pengolah sampah yang pertama, utamanya dalam memilah sampah (Septiani et al., 2019). Keterlibatan masyarakat dalam pengelolaan dan pengolahan sampah merupakan salah satu wujud pemberdayaan dalam pembangunan pedesaan di Kota Batu (Sulistyorini et al., 2015).

Kesuksesan pengelolaan sampah di Desa Tlekung yang melibatkan masyarakat ditunjukkan dari penggunaan gas metana untuk kebutuhan memasak sehari-hari dan digunakan untuk kegiatan lainnya yang membutuhkan daya gas. Gas metan yang dihasilkan dapat mencukupi kebutuhan bahan bakar rumah tangga sebanyak 300 kepala keluarga. Gas metana tersebut dialirkan dengan cara memanfaatkan tenaga blower yang dipasang di instalasi sanitary landfill untuk menghisap gas fermentasi sampah pada pipa lalu di uji coba di ITF setelah itu disalurkan ke masyarakat yang sudah terhubung dengan saluran gas tersebut. Pemanfaatan gas metana dapat digunakan sebagai pengurangan pemakaian energi listrik dan menurunkan emisi produksi energi fosil (Nurhadi et al., 2020).

Pengelolaan sampah berada dibawah pengawasan Dinas Lingkungan Hidup Kota Batu. Pekerja yang berjumlah 23 orang dan dibantu oleh masyarakat, mendapatkan upah Rp. 25.000 setiap harinya. Sumber dana untuk membayar tenaga kerja berasal dari dana APBN dan iuran warga untuk membayar kegiatan perawatan alat sanitary landfill yang dikelola oleh paguyuban masyarakat. Namun, demikian keberhasilan pengolahan sampah menjadi gas metan ditunjang oleh Dinas Lingkungan Hidup dan partisipasi masyarakat Desa Tlekung. 
Penelitian ini bertujuan untuk mengetahui bagaimana pihak TPA Tlekung mengelola sampah dan menanggulangi permasalahan bau sampah serta bagaimana tingkatan partisipasi masyarakat dalam pengelolaan sampah untuk menangani permasalahan bau sampah yang menyengat. Penelitian ini diharapkan memiliki manfaat untuk wilayah yang dijadikan sebagai TPA agar dapat termotivasi untuk mengurangi dampak bau yang dihasilkan dari tumpukan sampah tersebut dengan cara memberlakukan sistem sanitary landfill yang mengumpulkan fermentasi gas sampah, yaitu gas metan.

\section{BAHAN DAN METODE}

Penelitian dilakukan di Desa Tlekung, Kecamatan Junrejo, Kota Batu. Alasan pemilihan lokasi penelitian adalah keberadaan TPA dan posisi desa yang menjadi tujuan wisata di Kota Batu. Penelitian dilakukan pada bulan Oktober tahun 2020.

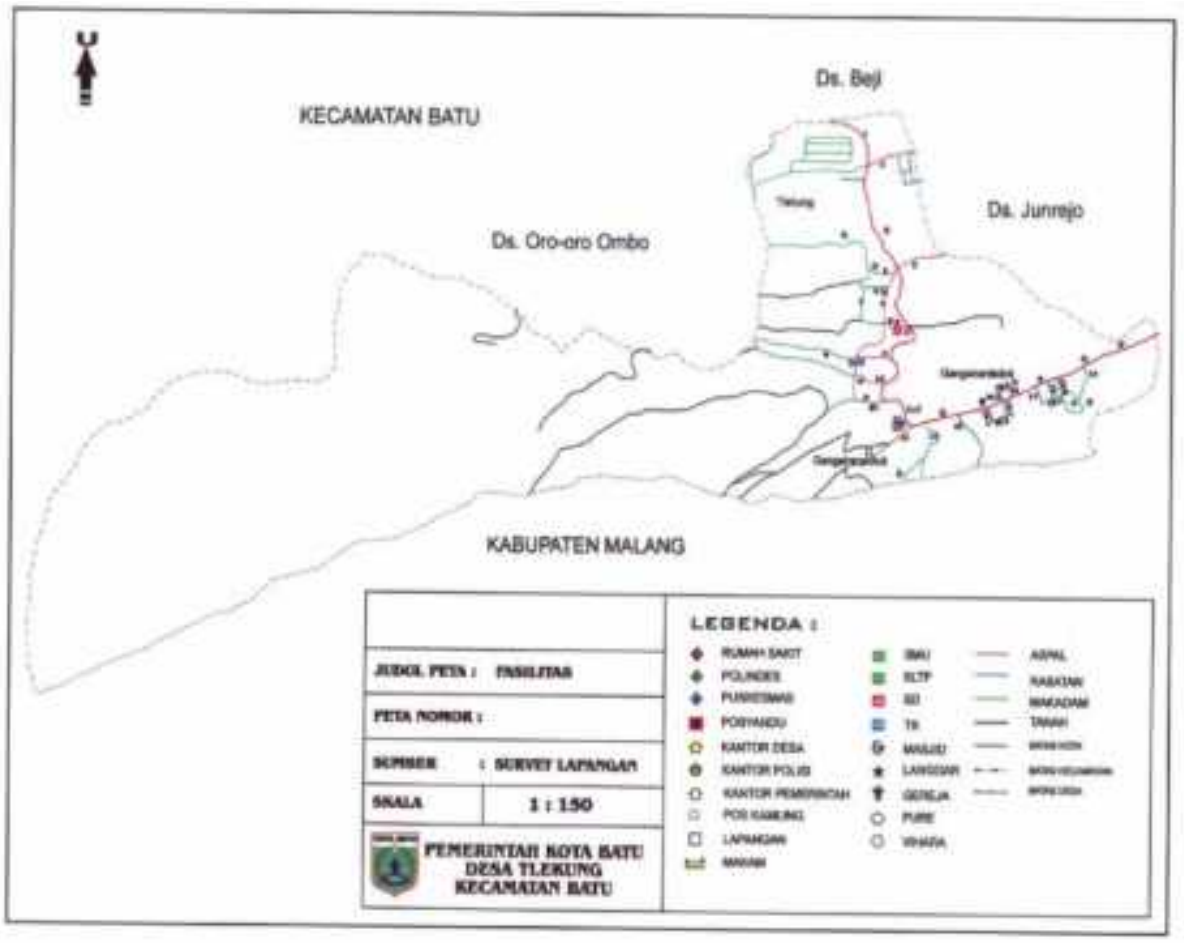

Gambar 1. Peta Desa Tlekung

Metode yang digunakan dalam penelitian ini adalah metode survei. Metode survei digunakan untuk mendapatkan data dari sampel sejumlah 30 kepala keluarga. Pengambilan sampel dilaksanakan dengan purposive sampling yakni menetapkan calon responden berdasarkan kriteria dan persyaratan oleh peneliti. Kriteria yang dimaksud yakni masyarakat yang terdampak bau sampah maupun terlibat dalam pengelolaan sampah di Desa Tlekung.

Pengumpulan data dilakukan dengan wawancara, literatur dan pengamatan di lapangan. Metode pengumpulan data primer dilakukan melalui wawancara kepada responden menggunakan kuesioner sejumlah 10 pertanyaan. Wawancara juga dilakukan kepada pengelola sampah di TPA Tlekung yang berjumlah 2 orang. Kegiatan pengamatan langsung di lapangan dilakukan untuk mengamati kondisi fisik pengelolaan sampah pemukiman di Desa Tlekung. Data sekunder diperoleh melalui dokumentasi. Dokumen yang dimakasud berupa data dan laporan dari beberapa pustaka pendukung penelitian.

Teknik analisis dalam penelitian ini adalah metode deskriptif. Data yang diperoleh dari responden di tabulasi dengan menjumlahkan skor yang didapat, pemberian skor didapatkan melalui indikator pengukuran tingkat partisipasi masyarakat.

Hasil skor yang diperoleh selanjutnya dikategorikan berdasarkan klasifikasi menurut, Martinawati, et al (2016). 
Salma Afifah, Edisty Anindira, Elvara Hana, Haldi Priya, M. Jalaludin, Nur Aini, Nurul Fadlilatus, Satti Wagistina | DLI 8 (2) (2021) 107-112 109

Tabel 1. Indikator tingkat partisipasi masyarakat

\begin{tabular}{llc}
\hline Indikator & Keterangan & Skor \\
\hline Pewadahan Sampah & Masyarakat tidak mewadahi sampah & 1 \\
& $\begin{array}{l}\text { Masyarakat mewadahi sampah dalam satu tempat (tidak } \\
\text { dipilah) } \\
\text { Masyarakat mewadahi sampah secara terpisah }\end{array}$ & 2 \\
& Masyarakat tidak berpartisipasi dalam retribusi sampah & 3 \\
Pengumpulan & $\begin{array}{l}\text { Masyarakat membakar sampah, menggunakan pelayanan } \\
\text { sampah namun tidak membayar retribusi }\end{array}$ & 2 \\
& $\begin{array}{l}\text { Masyarakat menggunakan pelayanan sampah dan membayar } \\
\text { retribusi sampah }\end{array}$ & 3 \\
\hline
\end{tabular}

Tabel 2. Klasifikasi tingkat partisipasi masyarakat

\begin{tabular}{cc}
\hline Tingkat Partisipasi & Persentase Skor \\
\hline Rendah & $0,00 \%-33 \%$ \\
Sedang & $34 \%-66 \%$ \\
Tinggi & $67 \%-100 \%$
\end{tabular}

Sumber: Martinawati, et al,. 2016

\section{HASIL DAN PEMBAHASAN}

\section{Proses Pengumpulan Sampah}

TPA Tlekung mulai dioperasikan pada bulan Juni 2009 untuk melayani 17 TPS di tiga kecamatan Kota Batu. Berdasarkan database Dinas Kebersihan Kota Batu, volume sampah yang diproduksi sebesar $475 \mathrm{~m}^{3} /$ hari dari sampah yang dihasilkan hanya 245 $\mathrm{m}^{3} /$ hari yang terangkut ke TPA sampah. Tingkat pelayanan kebersihan yang dilakukan di Kota Batu, baru 16 desa/kelurahan yang terlayani sedangkan 8 desa/kelurahan belum terlayani dengan baik. Pelayanan pengangkutan sampah di Kota Batu, Dinas Kebersihan memiliki 5 unit dump truck, 6 unit amroll truck, 1 unit open truck, dan 1 unit shovel. Selain itu sumber sampah yang berasal dari TPS melayani 116 unit gerobak sampah yang tersebar di berbagai titik di Kota Batu.

Pengumpulan sampah dari seluruh TPS selanjutnya diproses di TPA Tlekung yang berada di wilayah Desa Tlekung. Sampah yang masuk ke TPA memiliki komposisi $63 \%$ sampah organik, $36 \%$ sampah anorganik, dan 7\% sampah residu. TPA melakukan pemilahan sampah dengan 23 tenaga kerja khusus untuk memilah sampah dan memiliki kendala dalam melakukan pengerukan sampah, karena harus membeli tanah dari Kabupaten Malang dan membutuhkan biaya yang cukup besar sehingga dilakukan sistem pengumpulan dan pengolahan.

Sampah yang sudah dikumpulkan dan dipilah di TPA Tlekung lalu diolah berdasarkan jenisnya.
Sampah organik dikumpulkan dan dimasukkan ke dalam sanitary landfill agar limbahnya tidak mengganggu lingkungan sekitarnya dan dapat diolah menjadi gas metan dan pupuk, sedangkan sampah anorganik dan sampah lainnya dapat didaur ulang untuk dipergunakan lagi (Arief, 2013).

\section{Banyaknya Timbulan Sampah yang Dihasilkan}

Kota Batu merupakan salah satu daerah yang mengunggulkan sektor wisata terutama pada sektor agrowisata, sehingga banyak sampah-sampah yang ditimbulkan dari wisatawan (Dwiki, et al., 2020). Menurut Qodriyatun (2018), aktivitas pariwisata yang dilakukan antara wisatawan dengan pelaku wisata, dapat menyebabkan adanya timbunan sampah setiap harinya. Semakin meningkat jumlah kunjungan wisata pada destinasi wisata, maka volume sampah juga akan meningkat. Sampah organik maupun anorganik yang dikirim dari tempat-tempat destinasi wisata, seperti Jatim Park, Alun-Alun Kota, dan lain sebagainya yang kemudian membuat jumlah volume sampah yang ada di TPA Tlekung semakin meningkat. TPA Tlekung yang berada di Desa Tlekung bisa menerima sebanyak 80-110 ton lebih sampah dalam sehari dengan penyumbang sampah terbanyak berasal dari kegiatan di sektor pariwisata dan perdagangan buah-buahan serta sayur mayur yang berada di pasar.

\section{Dominasi Tipe Sampah}

Setiap harinya TPA Tlekung menerima 80-110 ton sampah, untuk mengurangi jumlah sampah setiap 
harinya Pemerintah Kota Batu melengkapi fasilitas Tempat Pengolahan Sampah Terpadu (TPST). Dari banyaknya sampah yang ada, masyarakat Desa Tlekung melakukan pemilahan sesuai dengan kategori sampah, terdapat kategori sampah organik dan sampah anorganik. Sampah organik dan anorganik sama-sama mendominasi sampah di Kawasan Desa Tlekung.

\section{Kegiatan Pengelolaan Sampah Menjadi Gas Metan}

Gas metan $\left(\mathrm{CH}_{4}\right)$ merupakan gas yang dibentuk oleh bakteri anaerob khususnya bakteri metanogenik (Marwah, Elin, \& Wowon, 2016). Bakteri tersebut ada dalam sampah yang mengandung bahan organik sehingga terbentuk gas metan. Bakteri tersebut bukan hanya terdapat pada sampah organik saja, tetapi juga terdapat di sampah anorganik. Permasalahannya pada sampah anorganik proses fermentasinya lebih lama dibandingkan dengan sampah organik.

Gas metan yang dihasilkan oleh TPA Tlekung merupakan hasil dari fermentasi sampah. Sampah organik dan anorganik yang ada pada TPA Tlekung diolah dengan tidak menambahkan zat-zat lainnya, sehingga gas metan yang dihasilkan di TPA Tlekung murni berasal dari penguapan sampah organik dan anorganik yang kemudian dikumpulkan dengan memanfaatkan pipa instalasi penangkapan gas metan. Pipa instalasi untuk gas metan dibuat berlubang dan dipasang di dalam tumpukan sampah organik. Menurut Mustaqim, et al (2010), Pipa instalasi merupakan suatu jaringan pipa yang digunakan untuk menyalurkan atau mendistribusikan biogas pada masyarakat sekitar.

Sebelum melakukan penyaluran, sesaat setelah fermentasi sampah terkumpul kemudian dihisap menggunakan blower dan dikeluarkan ke tempat pemrosesan gas metan di ITF (Intermediate Treatment Facility) untuk memastikan kelayakan dan keamanan gas metan tersebut lalu disalurkan ke rumah-rumah warga yang sudah terhubung dengan saluran gas (Armi, \& Dian, 2017).

\section{Pola Penyebaran Hasil Gas Metan}

Adanya bau tidak sedap dan menyengat dari tumpukan sampah di TPA Tlekung membuat masyarakat mengeluh tentang adanya bau tersebut, karena bisa berpotensi mengganggu kesehatan masyarakat yang tinggal di dekat area TPA Tlekung. Menurut Mulasari, Adi, \& Noeng (2016) dalam mengatasi adanya masalah tersebut dibutuhkan tanggung jawab pemerintah, sebagai salah satu bentuk pelayanan publik. Solusi dari pemerintah yang sudah berjalan untuk mengurangi dampak bau tersebut adalah dengan pembuatan sistem sanitary landfill. Sanitary Landfill merupakan sistem pengelolaan sampah dengan menutup tanah pada suatu lahan atau lokasi yang cekung, yang terdapat sampah di dalamnya (Susanti, Suwanto, \& Dzunuwanus, 2016). Proses sistem Sanitary Landfill tersebut menghasilkan sebuah produk yaitu berupa gas metan dan limbah lindi. Gas metan dapat dimanfaatkan oleh warga menjadi energi memasak untuk memenuhi kehidupan sehari-hari dan dapat dimanfaatkan untuk keperluan lainnya, sedangkan limbah lindi dapat dijadikan pupuk cair. Penggunaan gas metan menurut Insani (2013), dapat menjadi salah satu solusi sebagai bahan bakar alternatif untuk mengatasi mahalnya harga BBM, begitu pula dengan Liquid Petroleum Gas (LPG) yang semakin langka.

Awal pembuatan sistem sanitary landfill dan berhasil diuji coba untuk pengeluaran gas metan pada tahun 2016 terdapat 80 kepala keluarga yang mendapatkan saluran gas metan dari TPA Tlekung. Seiring berjalannya waktu sudah terdapat 300 kepala keluarga yang mendapatkan bantuan saluran gas metan di tahun 2018. Pihak DPRD sudah mengajukan tambahan bantuan kepada 500 kepala keluarga lainnya yang membutuhkan saluran gas metan kepada pihak TPA Tlekung.

\section{Bentuk Partisipasi Masyarakat dalam Pengelolaan Sampah Menjadi Gas Metan}

Terdapat tiga bentuk partisipasi masyarakat dalam pewadahan sampah yakni: (1) masyarakat tidak mewadahi sampah; (2) masyarakat mewadahi sampah dalam satu tempat (tidak dipilah); (3) masyarakat mewadahi sampah secara terpisah. Dari tabel tersebut diketahui bahwa persentase tertinggi adalah sekitar $56,6 \%$ yakni masyarakat telah mewadahi sampah secara terpisah yang dijelaskan secara rinci pada tabel 3.

Pada bentuk partisipasi pengumpulan juga dibagi menjadi tiga bentuk yakni: (1) masyarakat tidak berpartisipasi dalam retribusi sampah; (2) masyarakat membakar sampah, menggunakan pelayanan sampah namun tidak membayar retribusi dan masyarakat; (3) masyarakat menggunakan pelayanan sampah dan membayar retribusi sampah. menggunakan pelayanan sampah dan membayar retribusi sampah. Bentuk partisipasi masyarakat dalam menggunakan pelayanan sampah dan membayar retribusi sampah mencapai persentase tertinggi yaitu $56,6 \%$. 
Salma Afifah, Edisty Anindira, Elvara Hana, Haldi Priya, M. Jalaludin, Nur Aini, Nurul Fadlilatus, Satti Wagistina | DLI 8 (2) (2021) 107-112 111

Tabel 3. Hasil Bentuk Partisipasi Masyarakat

\begin{tabular}{|c|c|c|c|}
\hline No & Bentuk Partisipasi Pewadahan & Jumlah Responden & Persentase \\
\hline 1 & $\begin{array}{l}\text { Masyarakat tidak mewadahi } \\
\text { sampah }\end{array}$ & 2 & $6,6 \%$ \\
\hline 2 & $\begin{array}{l}\text { Masyarakat mewadahi sampah } \\
\text { dalam satu tempat (tidak } \\
\text { dipilah) }\end{array}$ & 11 & $36,6 \%$ \\
\hline 3 & $\begin{array}{l}\text { Masyarakat mewadahi sampah } \\
\text { secara terpisah }\end{array}$ & 17 & $56,6 \%$ \\
\hline No & $\begin{array}{l}\text { Bentuk Partisipasi Pengum- } \\
\text { pulan }\end{array}$ & Jumlah Responden & Persentase \\
\hline 1 & $\begin{array}{l}\text { Masyarakat tidak berpartisipasi } \\
\text { dalam retribusi sampah }\end{array}$ & 4 & $13,3 \%$ \\
\hline 2 & $\begin{array}{l}\text { Masyarakat membakar sam- } \\
\text { pah, menggunakan pelayanan } \\
\text { sampah namun tidak mem- } \\
\text { bayar retribusi }\end{array}$ & 9 & $30 \%$ \\
\hline 3 & $\begin{array}{l}\text { Masyarakat menggunakan pe- } \\
\text { layanan sampah dan mem- } \\
\text { bayar retribusi sampah }\end{array}$ & 17 & $56,6 \%$ \\
\hline
\end{tabular}

Sumber: Data lapangan, 2020

Tabel 4. Persentase Tingkat Partisipasi Masyarakat

\begin{tabular}{cccc}
\hline No & Tingkat partisipasi & Jumlah Responden & Persentase \\
\hline 1 & Tinggi & 28 & $93,3 \%$ \\
2 & Sedang & 2 & $6,6 \%$ \\
3 & Rendah & 0 & $0 \%$ \\
\hline
\end{tabular}

Sumber: Data lapangan, 2020

Pada tabel 4, berdasarkan 30 responden diperoleh tingkat partisipasi masyarakat dengan kategori rendah $0 \%$; sedang $6,6 \%$; dan kategori tinggi $93,3 \%$. Persentase tersebut menunjukkan masyarakat berpartisipasi secara aktif dalam pengelolaan sampah menjadi gas metan dengan mewadahi sampah secara terpisah dan menggunakan pelayanan sampah dan membayar retribusi sampah.

Berdasarkan hasil penelitian, masyarakat Desa Tlekung sudah melakukan pewadahan sampah untuk mempermudah pemilahan sampah saat di TPA dan masyarakat lebih memilih menggunakan pelayanan pengangkutan sampah dan membayar retribusinya. Walaupun masih ada masyarakat yang tidak melakukan pewadahan dan pengumpulan sampah, persentasenya kecil dari pada yang mau ikut berpartisipasi.

Adanya bentuk keluhan dari masyarakat terhadap bau dari tumpukan sampah, pihak TPA Tlekung membuat program sistem sanitary landfill yang dapat mengumpulkan gas metan untuk mengurangi dampak bau dari tumpukan sampah di TPA
Tlekung. Awal program sanitary landfill ini membutuhkan banyak sekali bantuan dari pihak masyarakat untuk menyelesaikan pengerukan tanah, pemasangan pipa di dalam tanah, pemasangan blower, dan pembangunan sanitary nya. Setelah pembangunan sanitary landfill selesai baru bisa dimulai kegiatan pengumpulan sampah untuk bisa berfermentasi di dalam sanitary tersebut.

Adanya pembangunan sanitary landfill ini membutuhkan perawatan pemeliharaan alat dan perbaikan alat jika mengalami kerusakan. Maka, pihak TPA Tlekung membutuhkan bantuan dari pihak masyarakat untuk membantu menjaga, merawat, dan memperbaiki alat. Akan tetapi, dari pihak masyarakat ada yang mengusulkan untuk dibuat paguyuban dengan tujuan setiap warga Desa Tlekung yang mendapat bantuan saluran gas metan untuk membayar kompensasi perawatan dan perbaikan alat sebesar Rp 10.000,00 setiap bulannya ke paguyuban tersebut lalu disetorkan ke pihak TPA Tlekung untuk dikelola. Usulan tersebut disetujui oleh pihak TPA Tlekung karena untuk biaya perawatan dan perbaikan 
alat membutuhkan biaya yang cukup besar serta disetujui oleh pihak masyarakat yang mendapatkan bantuan saluran gas.

\section{SIMPULAN}

Pengelolaan sampah menjadi gas metan memanfaatkan sampah organik dan anorganik yang dikumpulkan di sanitary landfill dan berfermentasi. Hasil fermentasi sampah yang mengalami penguapan masuk ke dalam pipa yang sudah ada, selanjutnya diserap oleh pipa instalasi dengan bantuan blower. Hasil akhir pengolahan sampah yang telah menjadi gas metan kemudian dialirkan menggunakan pipa ke rumah-rumah warga dan dimanfaatkan kembali oleh warga menjadi sumber energi untuk memasak.

Tingkat partisipasi masyarakat terhadap pengelolaan sampah menjadi gas metan tergolong tinggi yang mempunyai persentase 93,3\%. Masyarakat telah mewadahi sampah secara terpisah dan menggunakan pelayanan sampah dan membayar retribusi sampah. Partisipasi masyarakat Desa Tlekung menjadi suatu inovasi untuk mengurangi bau sampah dan membantu dalam pengolahan sampah menjadi gas metan untuk dapat dimanfaatkan oleh masyarakat sendiri. Keterlibatan masyarakat dalam pengelolaan dan pengolahan sampah juga menjadi salah satu wujud pemberdayaan dalam pembangunan perdesaan di Kota Batu.

\section{UCAPAN TERIMAKASIH}

Ucapan terimakasih penulis sampaikan kepada Bapak Nanang selaku pengurus di TPA Tlekung, Kepala Desa Tlekung, dan masyarakat yang telah membantu penulis untuk melakukan dan melaksanakan penelitian ini.

\section{DAFTAR PUSTAKA}

Arief, Sofyan. (2013). Pengelolaan Sampah Malang Raya Menuju Pengelolaan Sampah Terpadu Yang Berbasis Partisipasi Masyarakat. Fakultas Hukum, Universitas Muhammadiyah Malang. Volume 8: 195-208.

Armi., \& Dian. (2017). Pengelolaan Sampah Organik menjadi Gas Metana. Serambi Sanitia Vol.5 No.1 Tahun 2017. https://doi.org/10.32672/jss.v5i1.273
Dwiki, Amara., \& Widi. (2020). Kebijakan Pengelolaan Sampah di Daerah Utama Tujuan Wisata. Jurnal Kebijakan Publik Vol. 11, No. 2. http://dx.doi.org/10.31258/jkp.11.2.p.105-112

Insani, D. M. (2013). Degradasi Anaerob Sampah Organik dengan Bioaktivator Effective Microorganism-5 (EM-5) untuk Menghasilkan Biogas. Jurnal Pendidikan Sains, Vol.1 No.3. http://dx.doi.org/10.17977/jps.v1i3.4175

Martinawati, et al. (2016). Partisipasi Masyarakat dalam Pengelolaan Sampah Rumah Tangga: Sebuah Studi di Kecamatan Sukarami Kota Palembang. Jurnal Penelitian Sains Vol.18 No.1. https://doi.org/10.26554/jps.v18i1.35

Marwah, S., Ellin, H., \& Wowon, J. (2016). Analisis Kualitas Gas Metana dan Jumlah Bakteri Anaerob pada Proses Pembentukan Biogas dari Feses Sapi Potong dalam Tabung Hungate. E-Journals Vol. 5 No.3.

Mulasari, A., Adi, H., \& Noeng, M. (2016). Analisis Situasi Permasalahan Sampah Kota Yogyakarta dan Kebijakan Penanggulangannya. KEMAS 11 (2). https://doi.org/10.15294/kemas.v11i2.3989

Mustaqim, et al. (2010). Instalasi Sistem Penyalur Gasbio Menggunakan Pipa PVC.

Nurhadi, N., Windarta, J., \& Ginting, D. (2020). Evaluasi Pemanfaatan Gas TPA Menjadi Listrik, Studi Kasus TPA Jatibarang Kota Semarang. Jurnal Energi Baru Dan Terbarukan, 1(1), 19-25. https://doi.org/10.14710/jebt.2020.8134

Qodriyatun, S. N. (2018). Sampah Plastik: Dampaknya Terhadap Pariwisata dan Solusi. Info Singkat Vol. 10 No. 23.

Septiani, B. A., Arianie, D. M., Risman, V. F. A. A., Handayani, W., \& Kawuryan, I. S. S. (2019). Pengelolaan Sampah Plastik di Salatiga: Praktik, dan tantangan. Jurnal Ilmu Lingkungan, 17(1), 90. https://doi.org/10.14710/jil.17.1.90-99

Sulistyorini, N. R. Darwis, R. S., \& Gutama, A. S. (2015). Partisipasi Masyarakat dalam Pengelolaan Sampah di Lingkungan Margaluyu Kelurahan Cicurug. Social Work Journal Vol. 5 No.1. https://doi.org/10.24198/share.v5i1.13120

Susanti, E., Adhi, S., \& Dzunuwanus, G. (2016). Analisis Faktor Penghambat Penerapan Kebijakan Sanitary Landfill di TPA Jatibarang Semarang Sesuai Dengan Undang-Undang No. 18 Tahun 2008 Tentang Pengelolaan Sampah. Journal of Politic and Government Studies, 5(03), 371-383. 